\title{
Erratum to: An Assessment of the Necessary Strength of Behavioral Treatments for Severe Behavior Problems
}

\author{
John Northup ${ }^{1}$ - Wayne Fisher ${ }^{2}$ • SungWoo Kahng ${ }^{2}$. \\ Robert Harrell $^{2}$ - Patricia Kurtz ${ }^{2}$
}

Published online: 26 July 2017

(C) Springer Science+Business Media, LLC 2017

Erratum to: J Dev Phys Disabil (1997) 9(1):1-16

DOI: 10.1023/A:1024984526008

In the original published version of this paper, the third author's name was incorrectly written as Sung Woo Kahang. The correct name is shown above.

The online version of the original article can be found at http://dx.doi.org/10.1023/A:1024984526008

SungWoo Kahng

KahngS@health.missouri.edu

1 Louisiana State University, 236 Audubon Hall, Baton Rouge, LA 70804, USA

2 The Kennedy Krieger Institute and the Johns Hopkins University School of Medicine, Baltimore, MD 21218, USA 